\title{
PARTICULATE OPTICAL PROPERTIES IN THE MEDITERRANEAN AND BLACK SEAS THROUGH CALIPSO SPACEBORNE LIDAR MEASUREMENTS

\author{
Davide Dionisi $^{{ }^{*}}$, Vittorio Brando ${ }^{1}$, Gianluca Volpe ${ }^{1}$, Simone Colella ${ }^{1}$ and Rosalia Santoleri ${ }^{1}$ \\ ${ }^{1}$ Institute of Marine Sciences (ISMAR), Italian National Research Council (CNR), Rome - Tor Vergata, \\ Italy \\ *Email:davide.dionisi@cnr.it
}

\begin{abstract}
New applications on global-scale plankton retrievals using the CALIOP (Cloud-Aerosol Lidar with orthogonal Polarization) lidar measurements on the CALIPSO (Cloud-Aerosol Lidar and Infrared Pathfinder Satellite Observations) satellite recently suggested that space-based lidars could provide information about the depth distribution of optical scattering. Assessing the oceanic surface layer's optical properties through CALIOP is one of the reasons of the extension of the CALIOP mission for another 3 years (2018-2020). The objective of this work is the evaluation of the potential CALIOP ocean products in the Mediterranean and Black seas using the ocean color products provided by the Copernicus Marine Environment Monitoring Systems (CMEMS).
\end{abstract}

\section{INTRODUCTION}

The Lidar active remote sensing technique constitutes a highly reliable tool of investigating the marine environment. This technique allows detecting and determining the spatial and quantitative distributions of several optical and physical parameters of seawater with good resolution and accuracy at long distances. Lidar sensors operate in a range of conditions that are highly complementary to ocean color passive observations: under any lighting conditions; between broken cloud and through tenuous cloud; and through significant overlying aerosol loading with no need for complex correction algorithms.

Though originally designed for retrieving spatial and optical properties of clouds and aerosols, new applications on global-scale plankton retrievals using CALIOP (Cloud-Aerosol Lidar with Orthogonal Polarization) measurements suggested that space-based Lidars can provide information about the depth distribution of optical scattering
[1-3]. In particular, the surface hemispheric backscattering coefficients $\left(b_{b p}\right)$ at $532 \mathrm{~nm}$ (CALIOP emission wavelength) was estimated using the ratio between the cross-polarization and co-polarization channels. Despite these results, this new application for ocean retrievals has limitations and uncertainties that need to be further assessed and estimated.

The objective of this work is the evaluation of the potential CALIOP ocean products at basins scale. Within this frame, the ocean column-integrated depolarization ratio measurements at $532 \mathrm{~nm}$ were derived through CALIOP measurements in the Mediterranean (MED) and Black sea (BS). This parameter allowed deriving the backscattering coefficients that have been compared to the $b_{b p}$ at $443 \mathrm{~nm}$ and to the chlorophyll-a (Chl-a) derived by the multi-sensor L3 product (MODIS-AQUA and NPP-VIIRS data) in MED and BS provided by the Copernicus Marine Environment Monitoring Systems (CMEMS). Analyses of annual and seasonal distributions of CALIOP and CMEMS $b_{b p}$ are presented for both basins.

\section{DATA}

\subsection{CALIOP dataset}

To derive the ocean parameters, the CALIOP version 4.1 (V4.1) level 1 (L1) data products are used. Substantial improvements in the calibration accuracies and in the ancillary data used for the surface detection and calibration have been made for this data version. In particular, a new algorithm that estimates the likelihood of the saturation of the signal returning from the planetary surface was included in the analysis. This information, crucial for the retrieval of ocean product is reported as a flag value assuming the integer values of 0,1 or 2 for a not saturated, possibly saturated or certainly saturated detection 
channel, respectively [4]. More information about the data products can be found at the Atmospheric Science Data Center (ASDC) web site (https: //eosweb.larc.nasa.gov/project/calipso/calipso_tab le, last access: 29 march 2019).

\subsection{CMEMS Ocean product}

The Copernicus Marine Environment Monitoring Service (CMEMS) is one of the six services of the Copernicus programme. It provides regular and systematic reference information on the physical state, variability, and dynamics of the ocean, ice, and marine ecosystems for the global ocean and the European seas. For this work, we used, as reference products, the multi-sensor L3 product (MODIS-AQUA and NPP-VIIRS data) of $b_{b p}$ at $443 \mathrm{~nm}$ and Chl-a in the MED and BS. The nearreal-time multi-sensor processing chain set up to derive these products takes care of the band shifting, the inter-sensor bias correction, and sensor merging. Further details can be found in [5].

\section{METHODOLOGY}

CALIOP retrieval algorithm for ocean applications has been developed accordingly to the main retrieval procedures introduced by $[6,1$, 2]. The primary data set comprise the vertical profiles of co-polarized and cross-polarized component of the attenuated backscatter coefficients at $532 \mathrm{~nm}\left(\beta_{\mathrm{co}}\right.$ and $\beta_{\mathrm{cr}}$, respectively), with a vertical resolution of 30 meters (22.5 in water) and a single-shot along-track horizontal resolution of $330 \mathrm{~m}$. Firstly, to have a reliable $\mathrm{S} / \mathrm{N}$ for the $4^{\text {th }}$ bin below the surface at around $78 \mathrm{~m}$ depth, the shots along-track are averaged into 10 $\mathrm{km}$ profiles. Secondly, the following criteria are adopted:

-1) only profiles with surface peaks located within $\pm 120 \mathrm{~m}$ ( \pm 4 bins) of the surface Digital Elevation Model (DEM) parameter recorded in the CALIOP L1 data are considered.

-2) The surface backscatter signal for both $\beta_{\mathrm{co}}$ and $\beta_{\mathrm{cr}}$ should not be saturated (i.e. Surface_Saturation_Flag_532=0)

-3) The Integrated Attenuated Backscatter (IAB) should be lower than $0.017 \mathrm{sr}^{-1}$.
This preliminary filtering procedure reduces the original data sample of around $67 \%$.

The subsurface $\beta_{\mathrm{co}}$ and $\beta_{\mathrm{cr}}$ profiles are contaminated by the strong signal return from the ocean surface that is spread by CALIOP $532 \mathrm{~nm}$ photomultiplier tubes (PMTs) transient response over several adjacent range bins, due to the PMT's noise tail effect and low-pass filter's broadening effect [7-8]. These effects are removed following the de-convolution method proposed by [9] to water clouds and applied by [2] to water surface return. After this correction, only the corrected attenuated backscatter coefficient profiles ( $\beta_{\text {co_corr }}$ and $\beta_{\text {cr_corr }}$, respectively) that have all the first four bins below the surface with values greater than zero are selected. The corrected profiles, which corresponds to $20 \%$ of the original data sample, are used to compute the integrated total $\left(\delta_{\mathrm{T}}\right)$ and the ocean subsurface depolarization ratio $\left(\delta_{\mathrm{w}}\right)$, defined as follows:

$\delta_{T}=\frac{\sum_{i=p}^{i=p+5} \beta_{\text {cr_corr }}\left(z_{i}\right)}{\sum_{i=p}^{i=p+5} \beta_{\text {co_corr }\left(z_{i}\right)}}$

$\delta_{w}=\frac{\sum_{i=p+1}^{i=p+5} \beta_{\perp}^{\text {corr }}\left(z_{i}\right)}{\sum_{i=p+1}^{i=p+5} \beta_{\|}^{\text {corr }}\left(z_{i}\right)}$.

Finally, the column-integrated ocean subsurface lidar backscatter $(\gamma)$ is obtained combining (1), (2) and the ocean surface mean squares wave slopes $\left(\sigma^{2}\right)$ estimated using the wind speed from scatterometer ASCAT, OSCAT and from ECMWF analysis:

$\gamma=\frac{0.0209}{4 \pi \sigma^{2} \cos ^{4} \theta} \exp \left[-\frac{\tan ^{2} \theta}{2 \sigma^{2}}\right] \frac{\delta_{T}}{1-\delta_{T} / \delta_{w}}$.

The associated relative uncertainties $(\Delta \gamma / \gamma)$ is around 0.15 [2]. The $\gamma$ final horizontal resolution is $0.25^{\circ}$. 

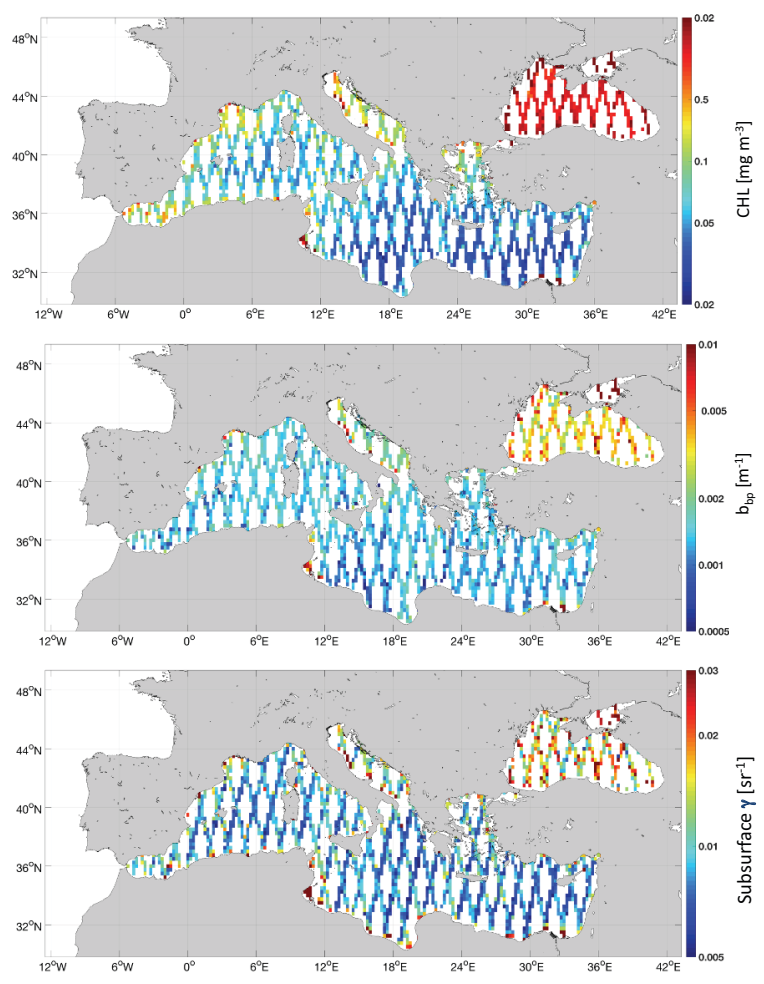

Fig.1 Distribution of Chl-a, $b_{b p}$ and $\gamma$ along the CALIOP groundtracks (high, middle and low panels, respectively) obtained from CMEMS computation and from eq. (3), respectively.

\section{RESULTS}

The CMEMS $b_{b p}$ and Chl-a products are compared to the $\gamma$ parameter obtained for Mediterranean (MED) and Black Sea (BS) (Fig.1). According to different 'trophic regimes' [10], MED is divided in four bioregions: West MED (1), East MED (2), Tyrrhenian Sea (3), Adriatic Sea (4). The correlation coefficients and the linear fit parameters $(a, b$ of $\log \mathrm{Y}=a \log \mathrm{X}+b)$ between $\gamma$ and $\mathrm{b}_{\mathrm{bp}}$ and $\gamma$ and CHL for the different sea regions are resumed in Table 1 and 2, respectively. For $\gamma$ and $b_{b p}$, an high correlation $(R \geq 0.8)$ is observed for the BS and the Adriatic Sea. A significant correlation is also calculated for West Med, whereas low signal and no correlation characterize no bloom regions (2 and 3 ). Conversely, no correlation is found between $\gamma$ and CHL except for the Adriatic Sea.

Table 1. Results of correlation coefficients and linear fit parameters $(a, b$ of $\log \mathrm{Y}=a \log \mathrm{X}+b)$ between $\gamma$ and $b_{\mathrm{bp}}$.

\begin{tabular}{|l|l|l|l|l|l|l|}
\hline $\boldsymbol{\gamma} \mathbf{~ v s ~ \mathbf { b } _ { \text { bp } }}$ & $\mathbf{1}$ & $\mathbf{2}$ & $\mathbf{3}$ & $\mathbf{4}$ & $\mathbf{M E D}$ & $\mathbf{B S}$ \\
\hline $\mathbf{N}^{\circ}$ of pts & 2678 & 7920 & 955 & 520 & 10905 & 1105 \\
\hline $\mathbf{R}$ & 0.35 & 0.35 & 0.50 & 0.57 & 0.32 & 0.09 \\
\hline $\begin{array}{l}\mathbf{a}, \mathbf{b}[\operatorname{logy}= \\
\mathbf{a l o g x + b ]}\end{array}$ & 0.83 & 0.73 & 0.73 & 0.65 & 0.77 & -0.01 \\
& 0.55 & 0.20 & 0.30 & 0.33 & 0.34 & -0.47 \\
\hline
\end{tabular}

Figure 2 depicts the mean annual cycles and the associated standard deviation of Chl-a, $b_{b p}$ and $\gamma$ (high, central and low panels, respectively) for MED and BS (blue and red colors). The summertime minima and wintertime maxima of the Chl-a signals (high panel of Fig.2) highlight that MED and BS have a similar phytoplankton biomass annual cycle. On the contrary, the $b_{b p}$ patterns show semi-annual and annual cycles for BS and MED, respectively. In terms of $\gamma$, there is a good accordance between $\gamma$ and $\mathrm{b}_{\text {bp }}$ for BS, whereas for MED the $\gamma$ annual cycle seems to agree with Chl-a.

Table 2. Results of correlation coefficients and linear fit parameters $(a, b$ of $\log \mathrm{Y}=a \log \mathrm{X}+b)$ between $\gamma$ and Chl-a.

\begin{tabular}{|l|l|l|l|l|l|l|}
\hline $\boldsymbol{\gamma}$ vs CHL & $\mathbf{1}$ & $\mathbf{2}$ & $\mathbf{3}$ & $\mathbf{4}$ & MED & $\mathbf{B S}$ \\
\hline $\mathbf{N}^{\circ}$ of pts & 2678 & 7920 & 955 & 520 & 10905 & 1105 \\
\hline $\mathbf{R}$ & 0.35 & 0.35 & 0.50 & 0.57 & 0.32 & 0.09 \\
\hline $\begin{array}{l}\text { a,b [logy } \\
\text { alogx }+\mathbf{b}]\end{array}$ & 0.83 & 0.73 & 0.73 & 0.65 & 0.77 & -0.01 \\
& 0.55 & 0.20 & 0.30 & 0.33 & 0.34 & -0.47 \\
\hline
\end{tabular}

\section{CONCLUSIONS AND PERSPECTIVES}

Particulate optical properties in the Mediterranean and Black seas were estimated through CALIPSO spaceborne lidar measurements. The obtained results show that the derived CALIOP ocean product $(\gamma)$ presents good correlation with the standard $b_{b p}$ ocean color product in optically complex waters (coastal and/or dominated by terrigenous load). Furthermore, $\gamma$ demonstrated to be as efficient as $b_{b p}$ and Chl-a parameters for the phytoplankton dynamics at seasonal and basin scales. Further studies are planned to validate not only the column integrated but also the subsurface profile of depolarization ratio. Within this frame, the analysis of ADM-AEOLUS measurements, with its observing geometry of $30^{\circ}$ off-zenith angle, could be used to evaluate the sub-surface signal contribution. 


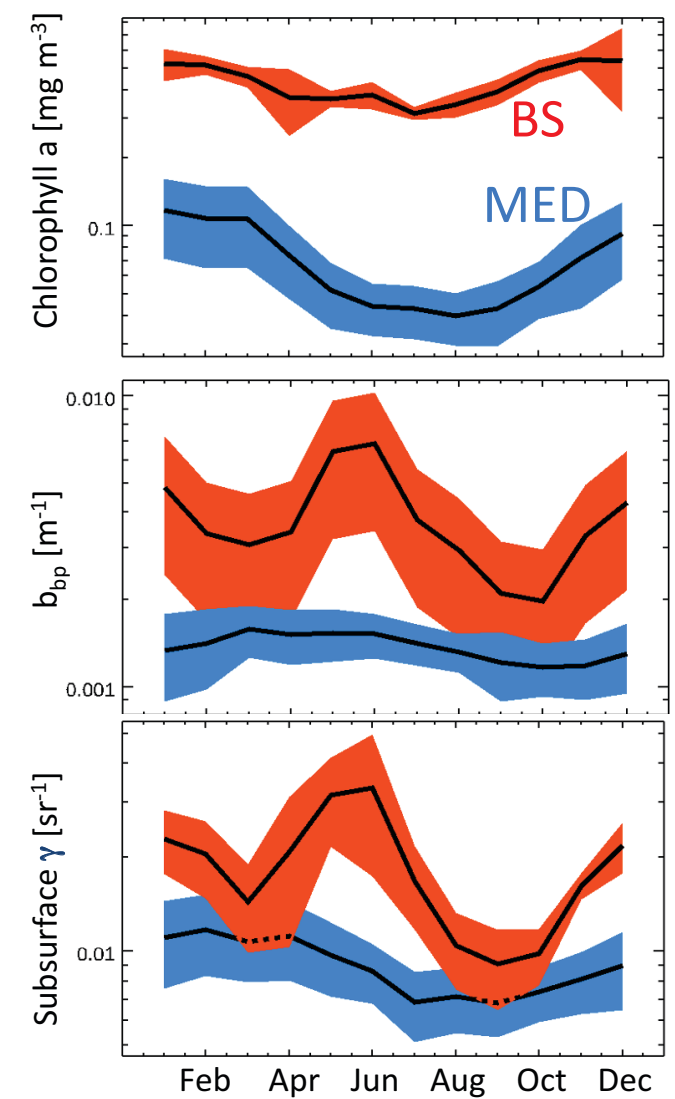

Figure 2. Mean annual cycles and the associated standard deviation of Chl-a, $b_{b p}$ and $\gamma$ (high, central and low panels, respectively) for MED and BS (blue and red colors).

\section{REFERENCES}

[1] Behrenfeld M.J., Hu Y., Hostetler C.A., Dall'Olmo G., Rodier S.D., et al.: Space-based lidar measurements of global ocean carbon stocks. Geophys. Res. Lett. 40:4355-60, 2013.

[2] Lu X., Hu Y., Trepte C., Zeng S., and Churnside, J.H: Ocean subsurface studies with the CALIPSO spaceborne lidar. J. Geophys. Res. 119, 4305-4317. doi: 10.1002/2014JC009970, 2014.

[3] Behrenfeld, M. J., Hu, Y., O’Malley, R. T., Boss, E. S., Hostetler, C. A., Siegel, D. A., Sarmiento, J. L., Schulien, J., Hair, J. W., Lu, X., Rodier, S., and Scarino, A. J.: Annual boom-bust cycles of polar phytoplankton biomass revealed by space-based lidar, Nat. Geosci., $10, \quad 118-122$, https://doi.org/10.1038/ngeo2861, 2017.

[4] Lu, X., Hu, Y., Yang, Y., Vaughan, M., Liu, Z., Rodier, S., Hunt, W., Powell, K., Lucker, P., and
Trepte, C.: Laser pulse bidirectional reflectance from CALIPSO mission, Atmos. Meas. Tech., 11, 32813296, https://doi.org/10.5194/amt-11-3281-2018, 2018. [5] Volpe, G., Colella, S., Brando, V. E., Forneris, V., La Padula, F., Di Cicco, A., Sammartino, M., Bracaglia, M., Artuso, F., and Santoleri, R.: Mediterranean ocean colour Level 3 operational multisensor processing, Ocean Sci., 15, 127-146, https://doi.org/10.5194/os-15-127-2019, 2019.

[6] Churnside, J., McCarty, B., and Lu, X.: Subsurface ocean signals from an orbiting polarization lidar, Remote Sens. 5(7), 3457-3475, 2013.

[7] Hu, Y., Powell, K., Vaughan, M., Tepte, C., Weimer, C., Beherenfeld, M., Young, S., Winker, D., Hostetler, C., Hunt, W., Kuehn, R., Flittner, d., Cisewski, M., Gibson, G., Lin, B., and MacDonnell, D.: Elevation information in tail (EIT) technique for lidar altimetry, Opt. Express, 15, 14504-14515, https://doi.org/10.1364/OE.15.014504, 2007.

[8] McGill, M. J., Vaughan, M., Trepte, C. R., Hart, W. D., Hlavka, D. L., Winker, D. M., Kuehn, R.: Airborne validation of spatial properties measured by the CALIPSO lidar, J. Geophys. Res., 112, D20201, doi:10.1029/2007JD008768, 2007.

[9] Li, J., Hu, Y., Huang, J., Stamnes, K., Yi, Y., and Stamnes, S.: A new method for retrieval of the extinction coefficient of water clouds by using the tail of the CALIOP signal, Atmos. Chem. Phys., 11, 29032916, https://doi.org/10.5194/acp-11-2903-2011, 2011. [10] D'Ortenzio, F. and Ribera d'Alcalà, M.: On the trophic regimes of the Mediterranean Sea: a satellite analysis, Biogeosciences, 6, 139-148, https://doi.org/10.5194/bg-6-139-2009, 2009. 